\title{
Measurement of the fasting urinary hydroxyproline: creatinine ratio in normal adults and its variation with age and sex
}

\author{
A HODGKINSON, T THOMPSON \\ From the MRC Mineral Metabolism Unit, The General Infirmary, Leeds LS1 3EX
}

SUMMARY Conditions for the determination of the fasting urinary hydroxyproline: creatinine ratio (OHPr: $\mathrm{Cr}$ ratio) have been examined, using a resin-catalysed hydrolysis and automated colorimetric procedure for the determination of hydroxyproline.

Feeding experiments with gelatin showed that hydroxyproline is rapidly absorbed and excreted in the urine and that a 12-hour (overnight) fast is sufficient to ensure correct and reproducible fasting OHPr: $\mathrm{Cr}$ ratios.

The mean fasting OHPr: $\mathrm{Cr}$ ratio decreased slightly with increasing age in both men and premenopausal women but there was no significant difference between the sexes. There was, however, a significant increase in the mean ratio in postmenopausal women. The normal range of fasting OHPr: Cr ratios for men and premenopausal women was found to be 0.003-0.015.

Hydroxyproline occurs mainly in collagen where it accounts for $13-14 \%$ of the total amino acid content. Urinary hydroxyproline is derived partly from collagen or gelatin-containing foods in the diet and partly from the breakdown of collagen in the body. On a collagen-free diet, the urinary excretion of hydroxyproline may be used to assess collagen metabolism and, in particular, the breakdown of bone, since most of the "endogenous" urinary hydroxyproline is derived from this source. ${ }^{12}$

Early studies of the diagnostic usefulness of urinary hydroxyproline made use of 24-hour excretion rates but these show wide normal variations, particularly in children, even on a gelatin-free diet. ${ }^{34}$ These variations are due mainly to differences in body mass of collagen which, in turn, is related to total body weight and to creatinine excretion. A narrower range of values is obtained if the daily excretion of hydroxyproline is related to the daily excretion of creatinine. To avoid the inconvenience of 24-hour urine collections, Nobbs et $a l^{6}$ proposed the determination of hydroxyproline: creatinine ratios (OHPr: $\mathrm{Cr}$ ratios) on single morning specimens with the subject on a meat and gelatin-free diet. Determinations on fasting urine samples provide a further simplification of the test since this eliminates the need for dietary restriction ${ }^{1}$ and in the present study

Accepted for publication 21 December 1981 we have evaluated the procedure proposed by Nor$\mathrm{din}^{7}$ in which OHPr: $\mathrm{Cr}$ ratios are determined on urine samples collected after a 12-hour fast. In particular, we have examined the rate of excretion of hydroxyproline following an oral load and the adequacy of a 12-hour fast for obtaining true fasting OHPr: Cr ratios. The effects of age and sex on the fasting OHPr: $\mathrm{Cr}$ ratio have also been examined.

\section{Material and methods}

Measurements were made on 144 healthy hospital workers aged 18 to $59 \mathrm{yr}$ ( 73 men and 71 women) and 17 women aged 46 to $65 \mathrm{yr}$ who attended a hospital clinic with peri- or postmenopausal symptoms associated with a natural menopause.

THE "TWO-HOUR" TEST

The subject is instructed to fast from $20.00 \mathrm{~h}$ on the evening before the test except for a cup of tea or equivalent light beverage before going to bed and again on rising the following morning. The bladder is emptied at about $08.00 \mathrm{~h}$ on the test day and this urine sample is discarded. A second sample is collected at about $10.00 \mathrm{~h}$ and this sample is retained for analysis. Various modifications of this procedure were made in order to determine the reliability of the test and these are detailed in the experimental section. 
Creatinine was determined by automatic colorimetry (Technicon Auto Analyser method AAII-11). Analytical grade reagents and glass distilled-deionised water were used throughout.

\section{ORAL DOSE OF HYDROXYPROLINE}

The hydroxyproline content of a typical ward diet averaged $3.89 \mathrm{mmol} /$ day (mean of four determinations). An oral dose of hydroxyproline, approximately equal to the normal daily intake, was prepared by making $4 \mathrm{~g}$ of gelatin into a jelly, flavoured with orange juice.

PROCEDURE FOR URINARY HYDROXYPROLINE The method is a combination of several earlier procedures $^{689}$ and incorporates a resin-catalysed hydrolysis of the urinary peptides, followed by oxidation of free hydroxyproline to pyrrole with chloramine $T$ and the reaction of pyrrole with $p$-dimethylaminobenzaldehyde to produce a "pink colour", the latter stages being carried out in a Technicon Auto Analyser.

\section{REAGENTS}

\section{Resin suspension}

Resin Amberlite CG-120 ( $\mathrm{Na}^{+}$form) type 11, 200 mesh, was converted to the $\mathrm{H}^{+}$form by mixing with $2 \mathrm{~N} \mathrm{HC1}$ and then washed repeatedly with water until the washings were neutral. The resin was dried overnight in an oven at $50^{\circ} \mathrm{C}$. Samples for hydrolysis were obtained by mixing $15 \mathrm{~g}$ of dry resin with $100 \mathrm{ml}$ of water, using a magnetic stirrer and then removing $2 \mathrm{ml}$ aliquots of the resin suspension with an automatic pipette (equivalent to $300 \pm 2 \mathrm{mg}$ of the dry resin).

\section{Elution buffer}

Anhydrous sodium acetate $(34.4 \mathrm{~g})$, trisodium citrate $7 \mathrm{H}_{2} \mathrm{O}(37.5 \mathrm{~g})$ and citric acid monohydrate $(5.5 \mathrm{~g})$ in one litre of water, adjusted to $\mathrm{pH} 6.0$ with acetic acid.

\section{Buffer for chloramine $T$}

Citric acid monohydrate $(50 \mathrm{~g})$, anhydrous sodium acetate $(72 \mathrm{~g})$, acetic acid $(12 \mathrm{ml})$ and $50 \%(\mathrm{wt} / \mathrm{vol})$ sodium hydroxide $(68 \mathrm{ml})$ in one litre of water, adjusted to $\mathrm{pH} 6.0$ with acetic acid.

\section{Chloramine $T$}

Chloramine $T$ was prepared immediately before use: $2.8 \mathrm{~g}$ was dissolved in $80 \mathrm{ml}$ of water and the following were added: methoxyethanol $(120 \mathrm{ml})$, buffer $(400 \mathrm{ml})$ and $30 \%(\mathrm{wt} / \mathrm{vol})$ Brij surfactant $(0.2 \mathrm{ml})$.
Perchloric acid

Perchloric acid $(270 \mathrm{ml}$ of $70 \%(\mathrm{vol} / \mathrm{vol}))$ was diluted to one litre with water.

\section{Erlich's reagent}

$p$-dimethylaminobenzaldehyde $(100 \mathrm{~g})$ in propan2-ol, (2l) filtered and stored in an amber glass bottle.

\section{Standards}

Stock hydroxyproline standard, $1 \mathrm{mmol} / \mathrm{l}$ hydroxyproline $(13.113 \mathrm{mg})$ in $100 \mathrm{ml}$ of water. Stored at $4^{\circ} \mathrm{C}$. Working standards ranging from 0.05 to $0.5 \mathrm{mmol} / \mathrm{l}$ were prepared immediately before use.

\section{PROCEDURE}

Sample or standard $(1.0 \mathrm{ml})$ was measured into a $10 \mathrm{ml}$ screw-capped tube (Sovirel, $16 \times 100 \mathrm{~mm}$, VA Howe \& Co Ltd, London SW6). Resinsuspension $(2 \mathrm{ml})$ was added and mixed thoroughly. Water $(6 \mathrm{ml})$ was added and centrifuged at $2000 \mathrm{rpm}$ for $10 \mathrm{~min}$. The supernatant fluid was removed by suction and discarded. Tubes were capped tightly and placed in an oven at $105^{\circ}$ for $16 \mathrm{~h}$ (overnight). They were then cooled, and elution buffer $(5 \mathrm{ml})$ was added and well mixed. Tubes were again centrifuged at $2000 \mathrm{rpm}$ for 5-10 min, and the supernatant fluid transferred to Auto Analyser sample cups. The manifold for the Auto Analyser was similar to that described by Grant ${ }^{8}$ but the flow rates were varied as follows: air $1.2 \mathrm{ml} / \mathrm{min}$; chloramine T $0.6 \mathrm{ml} / \mathrm{min}$; sample $0.6 \mathrm{ml} / \mathrm{min}$; perchloric acid $0.6 \mathrm{ml} / \mathrm{min}$; Erlich's reagent $0.7 \mathrm{ml} / \mathrm{min}$; sampler wash $1.2 \mathrm{ml} / \mathrm{min}$, waste line $1.6 \mathrm{ml} / \mathrm{min}$. The $\mathrm{OHPr}$ : $\mathrm{Cr}$ ratios were calculated as follows: hydroxyproline $(\mathrm{mmol} / \mathrm{l})$ : creatinine $(\mathrm{mmol} / \mathrm{l})$. The significance of the differences between mean values was calculated using Student's paired or unpaired $t$ test.

\section{Results}

VARIATION OF URINARY OHPR: CR RATIOS WITH DURATION OF FASTING

The variation of the urinary OHPr: $\mathrm{Cr}$ ratio with duration of fasting was examined after (a) normal food taken up to $20.00 \mathrm{~h}$, (b) normal food taken up to $20.00 \mathrm{~h}$, with the addition of $4 \mathrm{~g}$ of gelatin ingested at $20.00 \mathrm{~h}$. The results (Fig. 1) show that ingested hydroxyproline is excreted rapidly in the urine. Basal or near-basal conditions were reached after fasting for $12 \mathrm{~h}$, even after ingesting $4 \mathrm{~g}$ of gelatin (curve $B$ ) and there appeared to be no advantage in fasting for a further two-hour period since mean OHPr: $\mathrm{Cr}$ ratios obtained during the period 10.00 to $12.00 \mathrm{~h}$ did not differ significantly from those obtained in the previous two-hour period. Further evidence of the adequacy of the 


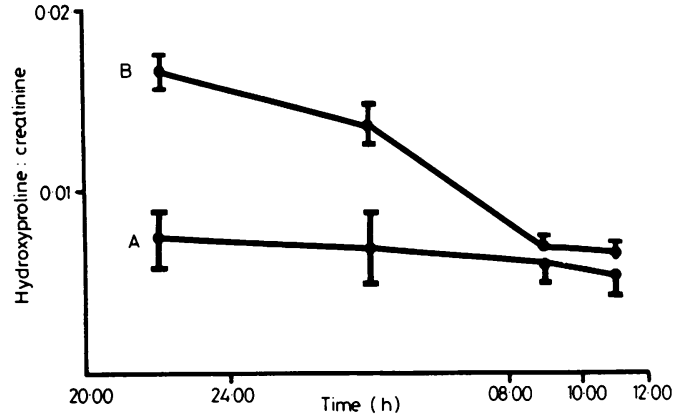

Fig. 1 Variation of urinary $\mathrm{OHPr}$ : $\mathrm{Cr}$ ratios with time (A) after normal food taken up to $20.00 \mathrm{~h}$. Mean values for seven subjects. (B) as for $A$ but with the addition of $4 \mathrm{~g}$ of gelatin, taken at $20.00 \mathrm{~h}$. Mean values for 18 subjects. Vertical bars denote $\pm S E M$.

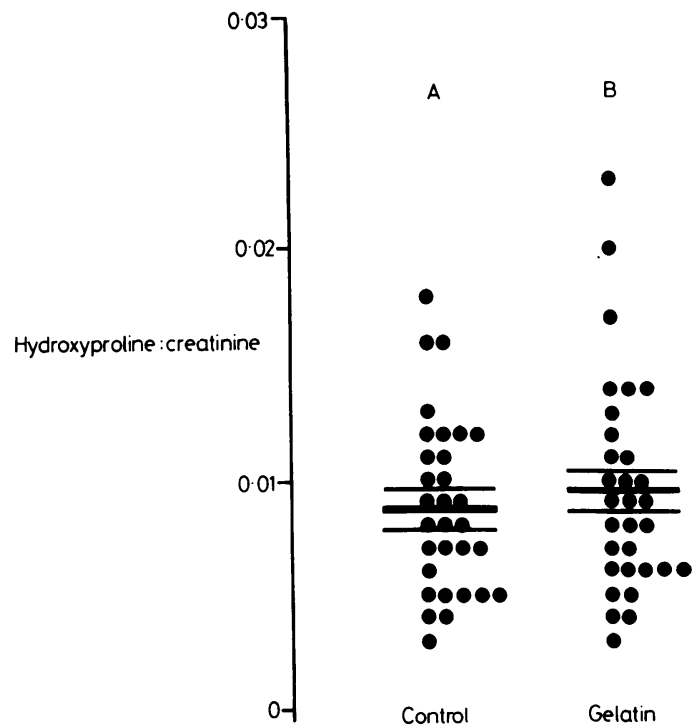

Fig. 2 Fasting urinary $\mathrm{OHPr}$ : $\mathrm{Cr}$ ratios $(A)$ after normal food. (B) after normal food plus $4 \mathrm{~g}$ of gelatin at $20.00 \mathrm{~h}$ in the same 31 subjects. Horizontal bars indicate the mean values $\pm S E M$.

08.00 to $10.00 \mathrm{~h}$ urine collection was obtained from studies on another 31 subjects, described below.

\section{COMPARISON OF FASTING OHPR: CR RATIOS}

AFTER NORMAL FOOD AND AFTER ORAL

HYDROXYPROLINE LOADING

The fasting OHPr: $\mathrm{Cr}$ ratio was determined in 31 subjects under the conditions described under "two-hour test." The test was repeated on the same subjects on the following day with the addition of gelatin, given as a single dose, at $20.00 \mathrm{~h}$ on the

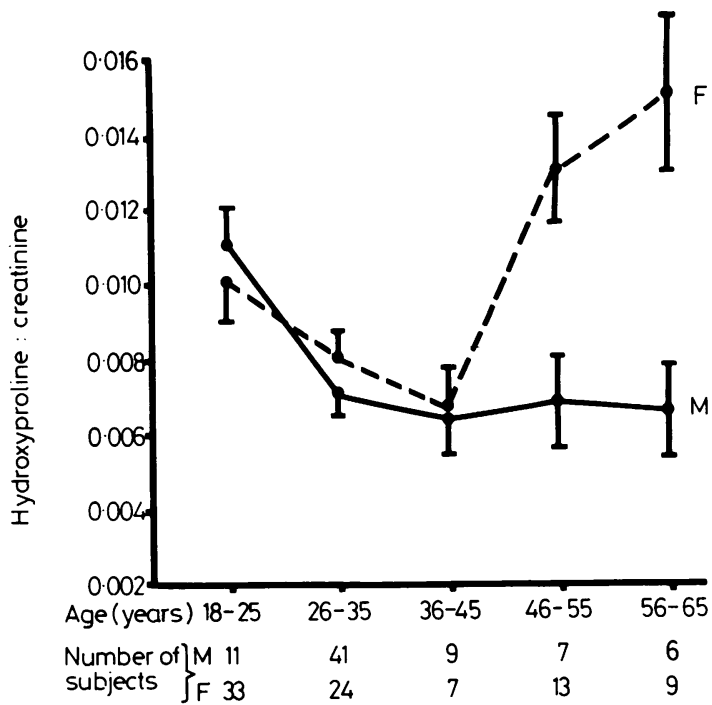

Fig. 3 Variation of the mean fasting OHPr: $\mathrm{Cr}$ ratio with sex and age. $M=$ male, $F=$ female. Vertical bars denote $\pm S E M$.

Reproducibility of the fasting urinary $\mathrm{OHPr}$ : $\mathrm{Cr}$ ratio

\begin{tabular}{lll}
\hline Subject No & \multicolumn{2}{l}{ OHPr: Cr ratio } \\
\cline { 2 - 3 } & Day 1 & Day 2 \\
\hline 1 & 0.013 & 0.014 \\
2 & 0.005 & 0.006 \\
3 & 0.007 & 0.006 \\
4 & 0.008 & 0.003 \\
5 & 0.004 & 0.005 \\
6 & 0.007 & 0.010 \\
7 & 0.005 & 0.008 \\
Mean & & \\
\hline
\end{tabular}

previous evening. The mean ratio was slightly higher after the gelatin load than after normal food (0.0095 compared with 0.0088 ) (Fig. 2) but the difference was not statistically significant $(p>0.05)$.

\section{REPRODUCIBILITY}

The fasting OHPr: Cr ratio was determined in seven subjects on two successive days, under the conditions described under "two-hour test" and the results are shown in the Table. There were some differences between the values obtained on successive days but the variations were generally small and the mean values for the seven subjects on days 1 and 2 were not statistically different $(p>0.05)$.

FASTING OHPR: CR RATIOS IN RELATION TO AGE AND SEX

Fasting OHPr: Cr ratios were determined in 144 
normal adults and the data were separated into 10 groups on the basis of age and sex (Fig. 3). The mean ratio was 0.011 in young men aged 18-25 yr but the value fell to between 0.006 and 0.007 in older men.

The pattern for women was similar to that for men in the earlier age groups but there was a marked divergence above the age of $45 \mathrm{yr}$, the mean value for women rising to 0.013 at age $46-55 \mathrm{yr}$ and to 0.015 at age $56-65 \mathrm{yr}$.

These increases were statistically significant when compared with women aged 36-45 yr $(\mathrm{p}<0.05$ and $<0.02$ respectively) and they were also higher than those of men of the same age $(p<0.01)$.

\section{Discussion}

Goverde and Veenkamp ${ }^{9}$ reported that urinary hydroxyproline values were about $9 \%$ lower after resin-catalysed hydrolysis than after acid hydrolysis. ${ }^{10}$ However, we found no significant difference between results obtained by the present method and those obtained after acid hydrolysis. ${ }^{11}$

The present results show that hydroxyproline is rapidly absorbed and excreted in the urine and that a 12-hour (overnight) fast is sufficient to ensure a true fasting OHPr: $\mathrm{Cr}$ value, even when the subject has ingested twice the normal daily intake of hydroxyproline. Urine collections made between 08.00 and $10.00 \mathrm{~h}$ yielded essentially the same results as collections made in the following two-hour period $(10.00$ to $12.00 \mathrm{~h})$. A 12 -hour fast has also been recommended prior to taking blood for the determination of plasma free hydroxyproline. ${ }^{1}{ }^{12} 13$

Some of the age-related variations shown in Fig. 3 have been reported previously. Absolute hydroxyproline excretion as well as OHPr: $\mathrm{Cr}$ ratios are appreciably higher in children than in adults. ${ }^{15}$ There is a gradual reduction in excretion between ages 17 and $24 \mathrm{yr}$ but it is not uncommon to see an occasional normal young adult whose hydroxyproline excretion is $2-3$ times the older adult average ${ }^{1}$ and this explains the slightly higher mean values in the 18-25 yr age groups. The significant rise in the OHPr: $\mathrm{Cr}$ ratio in women at the menopause has also been observed previously. ${ }^{14}$

Absolute hydroxyproline excretion is higher in young men than in young women, reflecting the difference in body collagen mass but this difference disappears after correcting for creatinine. ${ }^{1}$ However, the higher values seen in children and adolescents and in postmenopausal women persist after correcting for creatinine because the raised values are due to increased collagen breakdown rather than to differences in collagen mass. It is unlikely that many of the age-related changes in the OHPr: $\mathrm{Cr}$ ratio are due to changes in creatinine excretion per se since this remains relatively constant throughout adult life. ${ }^{15}$

The definition of a normal range is complicated by the substantial increase in the OHPr: $\mathrm{Cr}$ ratio in women at the menopause. However, if this group is excluded then over $95 \%$. of adults, both men and women, had values of less than $0 \cdot 015$. Conversely, over $97 \%$ had values exceeding 0.003 . The normal range of fasting OHPr: $\mathrm{Cr}$ ratios for men and premenopausal women may therefore be given as $0 \cdot 003-0 \cdot 015$. No attempt has been made to define a "normal range" for postmenopausal women.

We wish to thank Professor BEC Nordin for his interest and advice, Miss Moira Cummings for preparing the test diets and Mrs P Haikney, Mrs J Pentith and Mrs S Skerrow for skilled technical assistance. We also thank all the hospital laboratory workers who contributed to this study.

\section{References}

' Le Roy EC. The technique and significance of hydroxyproline measurements in man. Adv Clin Chem 1967;10:213-53.

${ }^{2}$ Saleh AEC, Coenegracht JM. The influence of age and weight on the urinary excretion of hydroxyproline and calcium. Clin Chim Acta 1968;21:445-52.

${ }^{3}$ Benoit FL, Theil GB, Watten RH. Hydroxyproline excretion in endocrine disease. Metabolism 1964;12:1072-82.

${ }^{4}$ Smiley JD, Ziff M. Urinary hydroxyproline excretion and growth. Physiol Rev 1964;44:30-44.

${ }^{5}$ Allison DJ, Walker A, Smith OT. Urinary hydroxyproline: creatinine ratio of normal humans at various ages. Clin Chim Acta 1966;14:729-34.

6 Nobbs BT, Walker AW, Davies TJ. A simplified method for the estimation of urinary total hydroxyproline. Clin Chim Acta 1975;64:219-21.

7 Nordin BEC. Diagnostic procedures. In: Nordin BEC, ed. Calcium, phosphate and magnesium metabolism. Edinburgh: Churchill Livingstone, 1976:480-1.

${ }^{8}$ Grant RA. Estimation of hydroxyproline by the Auto Analyser. J Clin Pathol 1964;17:685-6.

${ }^{9}$ Goverde BC, Veenkamp FJN. Routine assay of total urinary hydroxyproline based on resin-catalysed hydrolysis. Clin Chim Acta 1972;41:29-40.

${ }^{10}$ Prockop DJ, Udenfriend S. A specific method for the analysis of hydroxyproline in tissues and urine. Anal Biochem 1960;1:228-30.

"Hodgkinson A, Knowles CF. Laboratory Methods. In: Nordin BEC, ed. Calcium, phosphate and magnesium metabolism. Edinburgh: Churchill Livingstone, 1976:552-4.

${ }_{12}^{2}$ Prockop DJ, Keiser HR, Sjoerdsma A. Gastrointestinal absorption and renal excretion of hydroxyproline peptides. Lancet 1962;ii:527-8.

${ }^{13}$ Baumann H, Fritze E, Kallweit C. Der Hydroxyprolingehalt des Blutserums bei Gesunden und bei Silikosekranken. Klin Wochenschr 1964;42:786-8.

14 Crilly RG, Jones MM, Horsman A, Nordin BEC. Rise in plasma alkaline phosphatase at the menopause. Clin Sci 1980;58:341-3.

is Bulusu L, Hodgkinson A, Nordin BEC, Peacock M. Urinary 
excretion of calcium and creatinine in relation to age and body weight in normal subjects and patients with renal calculus. Clin Sci 1970;38:601-12.
Requests for reprints to: Dr A Hodgkinson, Assistant Director, MRC Mineral Metabolism Unit, The General Infirmary, Great George Street, Leeds LS1 3EX, England. 